\title{
Modernizando o emprego público*
}

Organização para Cooperação e Desenvolvimento Econômico - OCDE

\section{Introdução}

Os países da Organização para Cooperação e Desenvolvimento Econômico (OCDE) têm algo em comum quando se fala das particularidades de governo: um consistente núcleo de serviço público, ou seja, uma burocracia controlada centralmente, formada por pessoas que trabalham para os negócios de governo em ministérios, órgãos e agências com estruturas e sistemas próprios.

Estabilidade - ou o chamado emprego para toda a vida - e um regime especial são as características tradicionais do serviço público. Nas últimas décadas, entretanto, diversas áreas do serviço público perderam essa distinção, porque, com os processos de reforma, um número significativo de funções públicas passaram para o setor privado. Assim, muitas das suposições sobre como o serviço público funciona não são mais verdadeiras. 
Mas a questão é: a reforma do serviço público é uma simples questão de torná-lo mais parecido com o setor privado? Podem-se tratar os negócios de governo como qualquer outro negócio, ou os valores culturais do serviço civil nacional são importantes para a sociedade e precisam, assim, de salvaguardas no processo de reforma?

Este texto trata da reforma do emprego no núcleo do serviço público de países da OCDE, nas duas últimas décadas, assim como dos desafios e das questões que se colocam para o futuro. $\mathrm{O}$ estudo usa dados e informações de um recente survey sobre a gestão estratégica de recursos humanos em que também são comparadas as estruturas e práticas do serviço civil desses países.

\section{O que há de especial no serviço público?}

Todos os países da OCDE têm formas próprias de organização de seus empregados no núcleo do serviço público, que são especialmente desenhadas para promover ou preservar os valores que as sociedades consideram importantes para os que são responsáveis pela aplicação da lei ou pela realização da vontade coletiva. Por exemplo, esses valores devem incluir a idéia de que os servidores públicos não devem atuar de forma partidária. Embora tais arranjos existam em todos os países membros da OCDE, seus resultados e formas de governo não são iguais por causa das diferentes formas de liderança, gestão, valores e cultura.

Em muitos países, o principal desenho do serviço público foi criado a partir da idéia de que ele é um sistema diferente de outros sistemas existentes na sociedade. Justifica-se essa diferença pelos valores de governança que devem estar contidos no setor público. No entanto, nos últimos 20 anos, várias áreas do serviço público perderam sua singularidade e se tornaram bastante similares ao sistema geral de emprego. Mas isso significa que a idéia de serviço civil como bem constitucional, ou quase constitucional, que mantém a confiança no sistema governamental está desatualizada, mesmo que seja apenas em alguns países?

Ainda não temos uma resposta definitiva para essa questão, mas uma coisa é certa: se é para buscar no setor privado os modelos para modernizar o emprego público, não se pode esquecer que o objetivo fundamental do serviço público é governar e não gerenciar. Isso significa que se tem de prestar atenção a valores como integridade, eqüidade, justiça e coesão social, valores necessários para se manter a confiança no sistema político e governamental. Os aspectos gerenciais, embora importantes, devem ser considerados secundários.

A burocracia tradicional, centralmente controlada, é ainda um sistema robusto e funcional nos casos em que as instituições constitutivas da sociedade sofreram processos de descontinuidade e de interrupção e/ou naqueles em que as demais instituições não estão bem ordenadas. Esse sistema mostra-se também mais resistente em países em que a cultura nacional considera importante a existência de um conceito forte e abrangente de Estado e, por isso, precisa de consistência cultural para todo o núcleo central do serviço público.

Embora as tendências de modernização do emprego público venham ocorrendo rapidamente, muitos governos ainda adotam os principais elementos do sistema tradicional da administração pública. Não há, no entanto, um tipo ideal de emprego público, porque as sociedades enfrentam desafios e problemas muito 
diferentes. Por exemplo, um governo pode-se ver pressionado a ter um serviço público inovador e flexível, e outro pode ter urgência para melhorar a disciplina e a coordenação.

\section{Que tipo de serviço público?}

Há dois modelos básicos de emprego no núcleo central do serviço público dos países da OCDE - os que se baseiam em carreiras e os que se baseiam em postos profissionais. A escolha de um sistema ou de outro tem efeitos profundos no serviço público de um país.

Nos sistemas de carreira, os servidores tendem a passar toda sua vida de trabalho no setor público. $\mathrm{O}$ ingresso inicial dá-se por credenciais acadêmicas e/ou por concurso. Uma vez recrutadas, as pessoas são alocadas de acordo com o que as organizações requisitam. Pode-se também mudar de um ministério para outro ou de uma área de especialização para outra. A promoção é feita de acordo com um sistema de pontuação individual e não de um posto profissional específico. As principais características desse sistema são as limitadas possibilidades de se entrar no serviço civil no meio da carreira e uma forte ênfase no desenvolvimento da carreira. Nos sistemas que se baseiam em postos profissionais, a seleção é feita para adequar o melhor candidato para cada posto, seja por recrutamento externo ou por promoção interna. Esses sistemas são mais abertos e o ingresso lateral é relativamente mais comum.

$\mathrm{Na}$ verdade, nenhum serviço civil da OCDE é exemplo puro de um dos dois tipos de sistema. Há uma tendência para se adotarem processos de um modelo ou de outro, pois, dessa forma, otimiza-se o que existe de melhor em cada um dos modelos.
A República Tcheca, a França, o Japão, a Coréia e a Espanha têm as mais fortes características do sistema de carreira, enquanto o sistema de postos profissionais é adotado com mais freqüência em países que, nas duas últimas décadas, foram mais ativos nas reformas do setor público - Canadá, Islândia, Nova Zelândia, Suécia, Suíça e Reino Unido. O Reino Unido e a Suíça migraram de sistemas fortemente estruturados em carreiras

'Não há um

tipo ideal de emprego

público, porque as

sociedades enfrentam

desafios e problemas

muito diferentes. Por

exemplo, um governo

pode-se ver pressionado

a ter um serviço público

inovador e flexível, e

outro pode ter urgência

para melhorar a

disciplina e a

coordenação"

para sistemas de postos profissionais. É interessante observar que os países do Leste Europeu adotaram diferentes modelos de sistemas de serviço civil durante o período de transição, no início dos anos 90. A República Tcheca e a Polônia adotaram um sistema baseado em carreiras, enquanto a Hungria e República Eslovaca optaram pelo sistema baseado em postos profissionais. 
Pode acontecer de se adotar um modelo para os sistemas públicos nacionais como um todo, e haver diferenças entre os ministérios. Por exemplo, os ministérios de relações exteriores tendem a seguir o modelo baseado em carreiras porque os postos exercem diferentes graus de atratividade e também por conta das dificuldades de haver sistemas de controle formais para profissionais distribuídos no exterior.

Há quatro forças que influenciam o comportamento das organizações: os mercados, a regulação interna e externa, os contratos com parceiros internos ou externos e, finalmente, as pressões sociais que influenciam os comportamentos dos grupos ou dos indivíduos. Qualquer organização é influenciada por todos os quatros fatores, mas o resultado dessa influência pode ser diferente para cada uma delas. Aparentemente, há mais influência das pressões sociais no sistema de carreiras do que no de postos profissionais. No sistema de carreiras, a evolução do servidor público depende, em grande parte, de como ele é visto pela hierarquia da organização, excelente termômetro para moldar seu comportamento de acordo com as normas do grupo. Por outro lado, em sistemas baseados em postos profissionais, as exigências técnicas tendem a ser mais importantes e os indivíduos, menos suscetíveis a pressões sociais.

O desafio para os sistemas baseados em carreira é como prover um serviço civil capaz de dar respostas às demandas especializadas de uma sociedade contemporânea. E o desafio para os sistemas baseados em postos especializados é como assegurar que o interesse coletivo seja atendido. Trata-se apenas de "uma mexida e de um acerto" entre os dois enfoques? Infelizmente não é tão fácil assim. Os contratos dos sistemas de carreira oferecem a seus empregados, após o ingresso por concurso, possibilidades de mais progresso e de responsabilidades variadas. Introduzir desafios próprios dos sistemas profissionais nos sistemas de carreira pode implicar abalos no moral e na motivação dos funcionários. Por outro lado, fazer algumas modificações típicas dos sistemas de carreiras nos sistemas de postos profissionais, a menos que elas se destinem apenas a alguns postos claramente especificados, pode significar mexer no princípio da competição.

O sistema de carreira está sob pressão em todas as economias desenvolvidas do mundo, por não ser flexível e especializado, como exige o mercado de trabalho em geral. Há pouca evidência, no entanto, de que os países da OCDE que adotam esse sistema queiram eliminá-lo. $\mathrm{Na}$ verdade, em países de transição em que as principais instituições públicas e privadas passam por maiores transformações, parece ser mais apropriado um amplo sistema baseado em carreiras por causa da prioridade dada aos fundamentos da governança, o que não acontece com o gerencialismo.

Nos países desenvolvidos, há uma tendência de se adotar o sistema de postos profissionais. Mas a desvantagem é que os efeitos negativos desse sistema recaem sobre áreas importantes do governo, como o sentido de valores coletivos, de direção e de responsabilidade. Alguns países que focalizaram seu sistema de emprego público em postos profissionais terminaram por adotar medidas de proteção para evitar a perda de atributos culturais, sobretudo envidando esforços na construção de cultura coletiva no grupo sênior dirigente do governo. Fica no ar, porém, a preocupação de que esses remédios podem ser insuficientes quando o impacto das atuais políticas tiver atingido a cultura do seviço público. 


\section{Um emprego para toda a vida?}

O emprego estável e com mais garantia do que no setor privado tem sido adotado tradicionalmente no setor público dos países da OCDE. De fato, essa segurança no trabalho e os benefícios na aposentadoria fazem com que, em muitos países, os jovens acabem por buscar um emprego público. Essa situação vem mudando desde os anos 80. As diferenças entre o setor público e o privado estão diminuindo; a legislação está-se tornando mais flexível e os contratos por tempo determinado estão ficando mais comuns. Em 16 países, o status de emprego dos servidores civis é muito semelhante ao dos empregados em outros setores.

A mudança em direção a empregos mais temporários - distante, por tanto, das carreiras para toda a vida - parece ser uma realidade do mercado de trabalho contemporâneo. Tem mudado também a forma de recrutamento. Em muitos países da OCDE, cada vez mais recrutam-se trabalhadores do mercado. Independente da estratégia de recrutamento adotada, há semelhança nos princípios adotados: concurso aberto e seleção com base no mérito e na competência.

O tipo do sistema de serviço público de cada país influencia a natureza das reformas adotadas. Os sistemas de carreira que centralizam o recrutamento, o treinamento e a promoção vêm introduzindo reformas como, por exemplo, o concurso aberto e a gestão por objetivos. Por exemplo, a Itália e a Coréia começaram a incorporar a seus procedimentos tradicionais o recrutamento aberto como forma de aumentar a competição e a gestão com base no desempenho. Por outro lado, os sistemas baseados em postos profissionais, em que o recrutamento e o treinamento são descentralizados, começam a dar orientações centralizadas para que os valores coletivos sejam levados em conta durante o processo de seleção.

\section{Cortando os números do serviço público?}

Os anos 80 e 90 assistiram a vários governos fazerem cortes de pessoal para controlar o déficit público.

Em muitos casos, os cortes foram usados para introduzir as reformas gerenciais, mas as verdadeiras razões foram realmente de ordem econômica. Qualquer governo moderno precisa, periodicamente, sintonizar o emprego público com a economia. Nos anos 80 e 90, algumas nações fizeram uma opção radical ao redefinirem e estreitarem o papel do governo. Por exemplo, na Finlândia, as seis maiores empresas, de 1989 para 1990, mudaram seu status provocando uma diminuição de $10 \%$ no emprego público. Outra medida foi cortar empregos no serviço público existente, a exemplo do que a Alemanha e a Coréia fizeram. Esses cortes costumam ocorrer em resposta a problemas fiscais, que se transformam em crise política.

Pesquisas recentes da OCDE mostram que os cortes têm, em comum, crises políticas e imperativos políticos e administrativos. A idéia de que a causa dos cortes é de cunho político e não gerencial talvez explique por que eles têm resultado em perda de eficiência e de competência. Esses problemas, em nível micro, não exigem maiores razões para se tomarem ações drásticas de controle do emprego público. Há formas de desenvolver melhores estratégias de downsizing. 


\section{Liberdade para administrar?}

Embora a maioria dos países da OCDE adote uma gestão de recursos humanos bastante centralizada, verifica-se que, em pelo menos metade desses países, há um processo de descentralização.

O escopo e o ritmo da descentralização não são iguais, mas sabe-se que grande parte dos países da OCDE vem caminhando no sentido de conferir à gestão de recursos humanos mais flexibilidade e mais liberdade. Em geral, são três as estratégias adotadas: a) transferência da gestão de $\mathrm{RH}$ dos organismos centrais para os órgãos de linha; b) simplificação das regras e dos procedimentos; c) desenvolvimento de políticas mais flexíveis.

Um bom indicador para se saber qual o nível da descentralização é verificar se o controle do orçamento de pessoal saiu das agências centrais e passou para os órgãos. Devolver a autoridade orçamentária aos órgãos é tão importante quanto flexibilizar a responsabilidade da gestão dos recursos humanos: número de funcionários, classificação, nivelamento e folha de pagamento. Entre 1986 e 1993, houve devolução da autoridade orçamentária para área de pessoal nos seguintes países: Canadá, Dinamarca, Finlândia, Países Baixos, Nova Zelândia, Suécia e Reino Unido.

Em survey da OCDE sobre a administração estratégica de recursos humanos, verificou-se que a República Tcheca, a Eslováquia, a Islândia, os Países Baixos, a Nova Zelândia e a Suécia são os países em que houve mais delegação para os assuntos de pessoal. Áustria, Japão, Irlanda e Espanha são os mais centralizados. É necessário observar que, em geral, o sistema de postos profissionais caminha de mãos dadas com maior liberdade de gestão. Em muitos países, essa liberdade vem acompanhada por uma política de tornar os administradores responsáveis pelos resultados na gestão de pessoal e da organização.

Ainda não se sabe se a tendência do futuro é a descentralização. Sabe-se, entretanto, que, se houver uma tendência para contratos e acordos de desempenho com órgãos, a gestão passará a ter um papel mais estratégico no governo central.

Como administrar os servidores civis seniores?

Muitos países, após descentralizarem a gestão de recursos humanos, viram-se obrigados a se preocupar com seus servidores civis mais graduados.

Nos sistemas que se baseiam em postos de trabalho, o serviço civil sênior é formado por altos executivos e por um pool de potenciais altos executivos. Nos sistemas de carreira, o serviço civil sênior é formado por um escalão maior de servidores e pode abranger escalões inferiores e intermediários. Em geral, a definição de servidor civil sênior é determinada pela posição que ocupa. No entanto, em alguns países, especialmente na França e Coréia, usam-se também critérios pessoais, como, por exemplo, nível acadêmico ou posição na hierarquia. Em todos os países, o sistema de promoção baseia-se na avaliação de desempenho e nas competências pessoais.

Estudo da OCDE sobre as reformas em 12 países revela que os dois tipos de serviço civil estão evoluindo. Mostra também por que tanto o sistema de carreiras quanto o de posto de trabalho estão dedicando atenção à administração dos servidores civis seniores. No survey, realizado com 29 nações, ao se pedir explicação para a existência de um sistema separado para os servidores civis seniores, $71 \%$ dos países responderam que se trata 
de ferramenta para induzir uma cultura no serviço civil orientada para o desempenho. Para muitos países, os objetivos do sistema do serviço civil sênior são para garantir a mobilidade de pessoal entre os ministérios. $\mathrm{E}$, finalmente, o terceiro motivo, mais indicado pelo survey, foi o de desenvolver futuros líderes no setor público.

É interessante observar a atenção que os países onde foram feitas ambiciosas reformas vêm dando à formação de lideranças. Parece que perseguem dois objetivos conflitantes: o uso de lideranças individuais para fomentar melhor performance associada ao desejo de recompor a cultura coletiva do serviço civil, a qual sofreu grande desgaste com as tendências individualistas que caracterizam as mudanças gerenciais. $\mathrm{O}$ principal foco dos programas de desenvolvimento de lideranças é capacitar os indivíduos a melhorarem o desempenho do setor público. O objetivo coletivo, mais provável de ser atingido pela socialização que pelo treinamento em si, é uma das prioridades mais baixas. Há o risco de que, em longo prazo, essa dualidade de objetivos se configure em erro.

Claro que a coesão cultural só tem utilidade se for para melhorar a performance governamental. Em alguns países onde há um forte e coerente quadro de líderes, o foco em desenvolvimento de lideranças não serve apenas para melhorar o desempenho, mas também para abrir postos de direção para jovens e para novas idéias.

\section{Como modernizar as relações de trabalho?}

Existem três grandes tipos de relações de trabalho dos servidores públicos nos países da OCDE. Na Austrália, na Nova Zelândia e na Suécia, os servidores civis são regidos pelas mesmas leis dos empregados do setor privado. Um segundo grupo de países trata seus servidores da mesma forma que o setor privado, mas com algumas exceções, como, por exemplo, a polícia. O terceiro grupo é composto por países onde os servidores civis têm menos direitos trabalhistas do que os trabalhadores das empresas. De fato, em alguns países, a lei impõe limites às atividades sindicais dos servidores públicos.

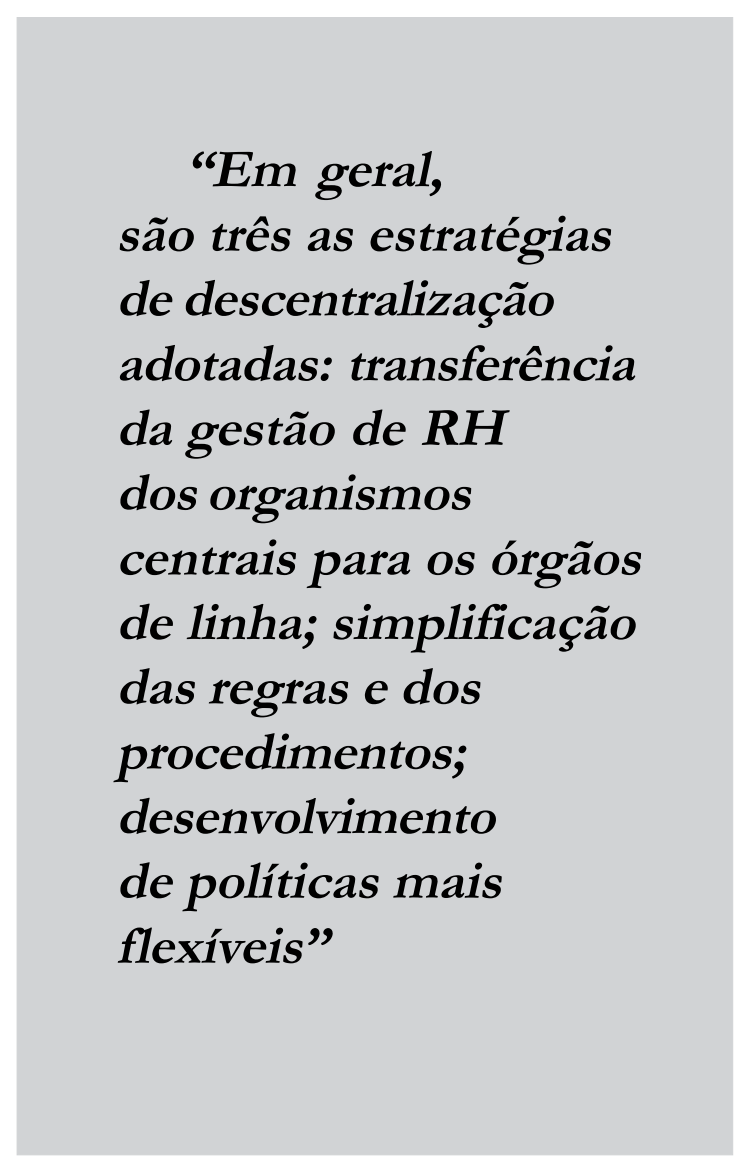

A influência dos sindicatos na vida desses trabalhadores se dá mais fortemente em áreas como: condições de trabalho, salários e a introdução de novos sistemas para o serviço público. Por outro lado, os sindicatos têm pouca influência em áreas como: desempenho, recrutamento e seleção e número de servidores.

As políticas de modernização do emprego e as mudanças no papel do 
Estado fizeram com que a influência dos sindicatos diminuísse em países como a Austrália, a Nova Zelândia e o Reino Unido. Isso não quer dizer que, obrigatoriamente, em outros países isso ocorra. A questão principal não é o que acontece no setor público, mas o que acontece na estrutura das relações de trabalho como um todo e também no quanto o governo de um país contribui para as taxas de emprego. $\mathrm{Na}$ atual
- envelhecimento da população - Nos próximos 5 a 15 anos, uma grande quantidade de servidores civis estará aposentando-se na maioria dos países da OCDE. Para enfrentar esse problema, os países estão assumindo iniciativas para reter os empregados mais velhos e reformar o sistema de aposentadoria (vide Figura 1).

- competição do mercado de trabalho - Os governos precisam competir por talentos

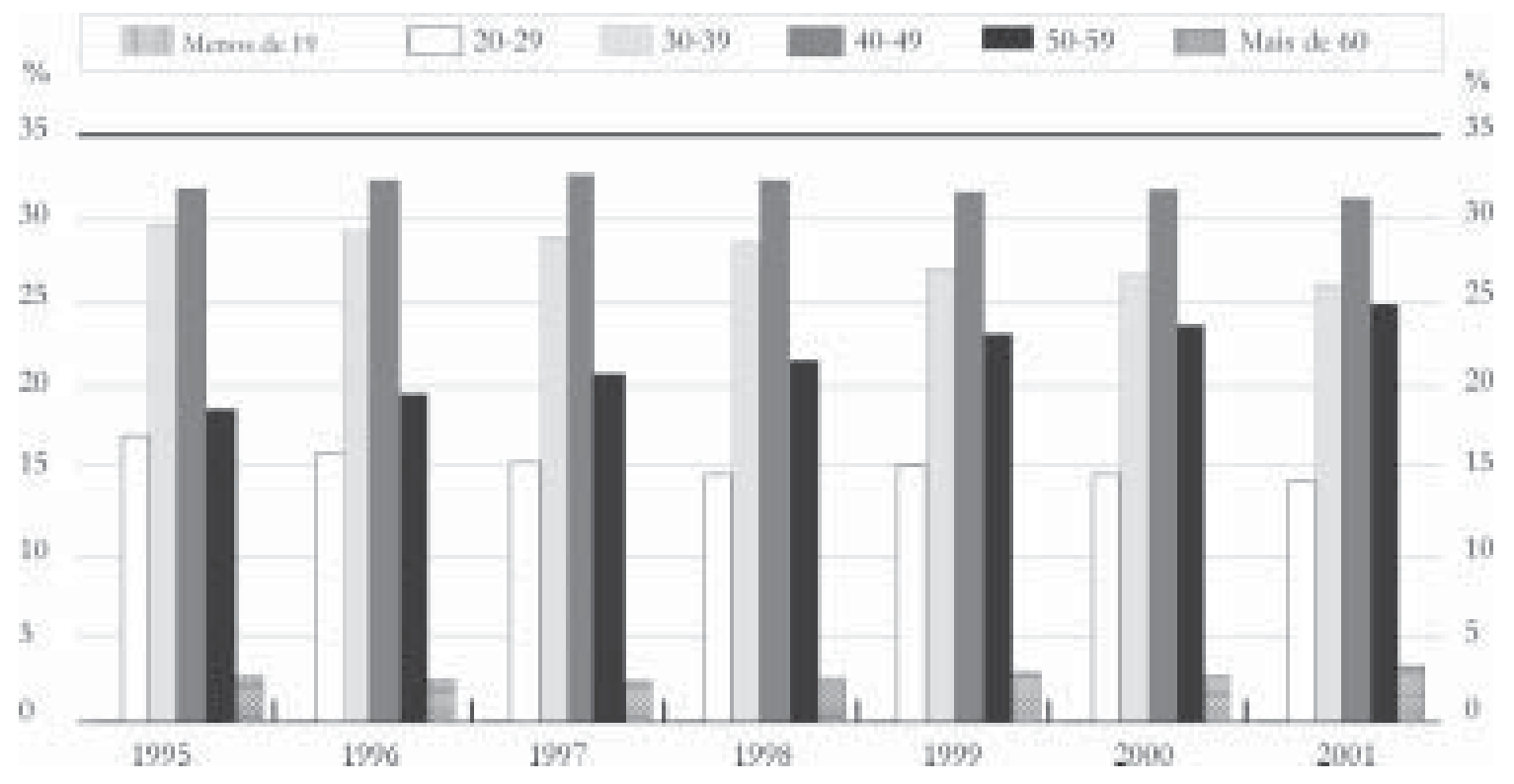

Figura 1: Evolução da idade média dos servidores públicos em alguns países da OCDE selecionados.

conjuntura fiscal, é possível que continue a haver conflitos entre governo e sindicatos nos países mais desenvolvidos da Europa. Até agora, não se sabe o que vai prevalecer, se a via inglesa, em que a influência dos sindicatos dos servidores públicos é pequena, ou se a via escandinava e irlandesa, com novos padrões de acordos governamentais.

\section{Insuficiência de servidores?}

Muitos países da OCDE vêm enfrentando uma crise nos quadros de servidores, pelas seguintes razões: com o setor privado. Profissionais altamente qualificados buscam mudar para as empresas privadas em busca de novas oportunidades e desafios, e os governos têm dificuldade para retê-los.

- a imagem do governo como empregador Os servidores civis perderam status na sociedade e boas condições de emprego. $O$ resultado é que jovens graduados não se sentem atraídos para trabalhar no setor público.

É para combater essa perda de competitividade do setor público como empregador que muitos governos estão tentando modernizar suas políticas de emprego. 


\section{Quem é o responsável?}

Todos os governantes da OCDE partilham o ideal de ter um serviço público profissional capaz de tomar decisões objetivas, oferecer serviço de qualidade para todos os cidadãos e se encarregar de dar continuidade ao sistema administrativo. Mas é também fundamental que, em cada país, os servidores públicos sejam responsabilizados pela vontade política do governante do momento. Como equilibrar as necessidades da continuidade profissional e a responsabilidade política é uma questão chave da governança pública.

Há uma enorme diversidade sobre a interface entre a administração e a política nos países da OCDE. Em alguns deles, a cada mudança de governo há novas indicações de executivos seniores para todo o serviço público. Em outros, o turnover é relativamente baixo. Há países em que a filiação a partidos é importante para a indicação do cargo; em outros, os servidores não podem, por questões de profissionalismo, alinhar-se a nenhum partido político. Há também nações que procuram criar uma cultura apolítica para o serviço público e há outras em que os grupos de lideranças envolvem políticos e servidores públicos.

Qual o melhor caminho? A única resposta a essa questão está no contexto dos acordos constitucionais e culturais de cada sociedade. Em todos os sistemas, a cultura do profissionalismo é incentivada independentemente do processo adotado para a indicação dos escalões superiores. Em alguns sistemas, não é importante dispor de serviço público formalmente apolítico, porque há outras formas de controle do poder político, como um legislativo forte, um sistema estatutário bem desenvolvido, além de limitações judiciais sobre o poder político, ou mesmo uma poderosa cultura de profissionalismo partidário.

O que fica evidente é que algumas das mudanças nas práticas de emprego da OCDE causam impacto na interface político-administrativa. Por exemplo, em países de tradição "Westminster", se, por um lado, cada vez mais se faz uso da proteção estatutária (por exemplo, os reguladores econômicos), por outro, aumenta-se o número de indicações políticas por parte de ministros.

\section{$\mathrm{E}$ agora, o que vai acontecer?}

Nas últimas duas décadas, as principais tendências de modernização do emprego público foram influenciadas por uma série de fatores, como o surgimento de problemas novos, mudanças no mercado de trabalho e novas idéias de gestão. A conclusão mais importante desse estudo da OCDE é que os dois sistemas arquétipos do serviço público - o de carreira e o de postos profissionais - estão, ambos, sob pressão. Verificou-se também que as ações tomadas até o momento são adaptações ou instrumentos usados para responder a determinados problemas, sem dar atenção ao impacto que se pode produzir no sistema da gestão pública como um todo. É necessário, no entanto, dar maior atenção a esses assuntos sistêmicos e, em particular, a três dilemas fundamentais:

- a dificuldade de os governos atraírem e manterem profissionais capazes de atender demandas cada vez mais qualificadas e de alta qualidade;

- a interconexão dos problemas públicos, a fragmentação da ação pública e a individualização das responsabilidades e dos incentivos do serviço público; e

- a necessidade de atrair e motivar executivos seniores que respondam às 
demandas de alta performance de um ministério moderno e, ao mesmo tempo, os mantenha em um governo cuja tradição é o interesse público.

Conclui-se também que essa importante área de debate e de ações da gestão pública nos países da OCDE ainda se encontra em estágio relativamente imaturo. Em médio prazo, parece que os países com sistemas baseados em carreiras estarão trabalhando para incorporar mais pressões de mercado, enquanto os que têm sistema de postos profissionais estão buscando formas de fortalecer a coesão cultural. Não está claro ainda qual das atuais modificações se transformará na tendência preponderante.

\section{Nota}

*Este artigo foi publicado originalmente pela OCDE, em inglês e francês, com os títulos: "Policy brief : Public sector modernisation: modernising public employment"; "Synthèse : la modernisation du secteur public: moderniser l'emploi public".OECD, 2004. All rights reserved. A qualidade da tradução para o português e sua coerência com o texto original é de responsabilidade da ENAP Escola Nacional de Administração Pública. Tradução: Mônica Lúcia R. Fernandes. 